International Journal of MCH and AIDS (2018), Volume 7, Issue 2, 226-234

\begin{tabular}{ll}
\hline & INTERNATIONAL JOURNAL \\
& of MCH and AIDS \\
& ISSN 216I-864X (Online) \\
IJMA & ISSN 216I-8674 (Print) \\
& DOI: I0.21 I06/ijma.9I \\
\hline
\end{tabular}

ORIGINALARTICLE

\title{
Assessment of PMTCT Success Rates Based on Antiretroviral Interventions and Feeding Options: A Prospective Cohort Study
}

\author{
Kolawole A. Fasakin, Ph. D;, Christopher T. Omisakin, MSc;,9 Idowu O.Adebara, MBBS, FMCOG;,3, \\ Wasiu A.Ajetunmobi, MBBS, FWACPaed;,4, Adebayo A. Adeniyi, MBBS, FMCOG, FWACOG;5,9 \\ Ayodele J. Esan, MSc;, Olufunke B. Bolaji, MBBS, FMCPaed;, Oluwafemi D. Ajayi, MSc;, \\ Abayomi J.Afe, MBBS, MPH, Ph.D, MRCOG ${ }^{10}$
}

\begin{abstract}
'Blood Transfusion Laboratory, Department of Haematology and Blood Transfusion, Federal Teaching Hospital, P.M.B 20I, Ido Ekiti, Ekiti State, Nigeria;2PEPFAR-Supported ART Laboratory, Department of Haematology and Blood Transfusion, Federal Teaching Hospital, P.M.B 20I, Ido Ekiti, Nigeria; ${ }^{3}$ Department of Obstetrics and Gynaecology, Federal Teaching Hospital, P.M.B 20I, Ido Ekiti, Ekiti State, Nigeria; ${ }^{4}$ Department of Paediatrics, Federal Teaching Hospital, Ido Ekiti, P.M.B 20I, Ido Ekiti, Ekiti State, Nigeria; ${ }^{5}$ Department of Obstetrics and Gynaecology, Federal Teaching Hospital, P.M.B 20I, Ido Ekiti, Ekiti State, Nigeria; ${ }^{6}$ General Haematology Laboratory, Department of Haematology and Blood Transfusion, Federal Teaching Hospital, P.M.B 20I, Ido Ekiti, Ekiti State, Nigeria; ${ }^{7}$ Department of Paediatrics, Federal Teaching Hospital, Ido Ekiti, P.M.B 20I, Ido Ekiti, Ekiti State, Nigeria; ${ }^{8}$ Blood Transfusion Laboratory, ABUAD Multi-System Hospital,Ado Ekiti, Ekiti State, Nigeria; ${ }^{9}$ College of Medicine and Health Sciences, Afe Babalola University, Ado Ekiti, Ekiti State, Nigeria; ${ }^{10}$ Department of Community Medicine, Equitable Health Access Initiative, Lagos, Nigeria.

Corresponding author email: fasakin_kolawole@yahoo.co.uk
\end{abstract}

\section{ABSTRACT}

Background:The success of any prevention of mother-to-child transmission (PMTCT) program is assessed by the proportion of HIV-exposed infants that sero-convert at the end of all risk exposures. Although adopting the best feeding option for HIV-exposed infants is one of the factors that impact PMTCT outcomes, there is limited data on the assessment of PMTCT success rates based on antiretroviral interventions and feeding options. This study assesses the success rate of PMTCT service based on antiretroviral interventions and feeding options.

Methods: Eighty-five HIV-infected mothers previously in care were enrolled in a prospective cohort study. Folders and structured questionnaires were used to extract data on mother-infant pair and the first CD4, count of infected mothers on enrolment at PMTCT clinic. Dry blood spot samples were obtained from exposed infants for early infant diagnosis. Results were analyzed using the SPSS software.

Results:The mean age of enrolled mothers was $31.3 \pm 4.4$ years, and an average CD4+ T-lymphocyte count of $368.6 \pm 216.2$ cells/ $\mu$ I. Seven $(8.2 \%)$ of the HIV-exposed infants were positive for HIV-I based on early infant diagnosis results. Overall PMTCT success rate (PMTCTSR) was $91.8 \%$. HIV-I prevalence of $5.0 \%, 0 \%$ and $21.1 \%$ was found among infants of patients who opted for breastfeeding, replacement feeding, and mixed feeding respectively thus yielding PMTCT success rates of $95 \%, 100 \%$ and $78.9 \%$. Pediatric antiretroviral interventions success rates in HIV-exposed infants was $95.8 \%, 80.0 \%$ and $66.7 \%$ based on age groups $\leq 6$ months, $>6 \leq 12$ months, and $>12 \leq 18$ months respectively.

Conclusion and Global Health Implications: Quality PMTCT service is vital for successful prevention of mother-to-child transmission of HIV. Implementation of more dynamic approaches such as adherence to option B+ guidelines in PMTCT service in our settings can further reduce mother-to-child transmission of HIV and improve outcomes.

Key words: Assessment • Antiretroviral Interventions • PMTCT • Success Rates • Feeding Options • Cohort 
Copyright (C) 2018 Fasakin et al.This is an open-access article distributed under the terms of the Creative Commons Attribution License, which permits unrestricted use, distribution, and reproduction in any medium, provided the original work is properly cited.

\section{Introduction}

\section{Background of the study}

Mother-to-child transmission (MTCT) of human immunodeficiency virus (HIV) is a major public health problem and its prevention is vital in curtailing HIV acquisition among children.' Mother-to-ChildTransmission of HIV accounts for over $90 \%$ of HIV infections in children, ${ }^{2,3}$ and Nigeria has the highest number of new HIV infections among children. Motherto-child transmission accounts for up to $14 \%$ of new HIV infections globally. ${ }^{4-5}$ The risk of transmission in the absence of any intervention by an infected mother is estimated to be $15-25 \%$, which increases significantly to $20-45 \%$ when infants are breastfed. ${ }^{6}$ Prevention of mother-to-child transmission (PMTCT) interventions reduces the risk of transmission to less than $5 \%$ if strategies are adhered to during pregnancy, labor, delivery and breastfeeding. ${ }^{7}$ These interventions involve holistic approaches that range from administration of antiretroviral therapy for the mother, a short course of antiretroviral drugs for the baby, adoption of measures to prevent HIV acquisition in the pregnancy and right choice of feeding options. Based on 2014 sentinel survey, national HIV seroprevalence rate among pregnant women in Nigeria was $3.0 \%$ (ranging from $0.9 \%$ to $15.4 \%$ across various geopolitical zones) ${ }^{8}$ compared with $5.8 \%$ obtained from an earlier survey conducted in 200I. The reduction is likely connected with improvement in scale up of PMTCT programs. Several authors have reported different aspects of PMTCT including scale up of HIV counselling and testing for pregnant women and treatment of all HIV-infected pregnant women irrespective of their CD4 count initiation of post-exposure prophylaxis for HIV-exposed infants and choice of appropriate feeding options and the World Health Organization recommends excluding breastfeeding for the first six months of life of exposed infants. ${ }^{9-15}$

Where replacement feeding is recommended, it must be Acceptable, Feasible, Affordable, Sustainable and Safe (AFASS). ${ }^{14,15}$ Mixed feeding is not encouraged

๑ 2018 Global Health and Education Projects, Inc. because of associated high risk of HIV transmission to infants of HIV-positive mothers and infant mortality but for undisclosed reasons, some enrolled mothers opted to feed their infants. The purpose of this study was to examine how the choices of feeding options by HIV-infected mothers in combinations with antiretroviral interventions affected PMTCT outcomes. This was a baseline assessment of PMTCT success rate of PMTCT services in our facility aimed at enhancing policy formulation, program planning, and establishment of patient clinical benefits.

\section{I Objectives of the study}

The objective of this study was to assess the PMTCT services success rate at this facility, the only federal tertiary health institution in rural area of Ekiti state that offers anti-retroviral therapy (ART)/ PMTCT service, to determine the extent to which the facility met its set goal of achieving less than $5 \%$ mother-to-child transmission of HIV.

\section{I.2 Specific aims and hypothesis}

Specifically, the study: I) assessed if certain social demographic characteristics affect PMTCT outcomes; 2 ) assessed the impact of the mean CD4 counts of enrolled mothers categorized based on infants HIV-status and feeding options on PMTCT outcomes; 3) assessed PMTCT success rates among enrolled mothers based on antiretroviral therapy interventions period and feeding options; 4) determined the prevalence of mother-to-child transmission of HIV-I among exposed infants; and $5)$ determined the pediatric antiretroviral success rates among HIV-I exposed infants. We hypothesised that Antireroviral interventions and feeding options will influence PMTCT outcomes in this population.

\section{Methods}

This was a prospective cohort study designed to assess the PMTCT success rate based on the antiretroviral interventions and feeding options of pregnant women enrolled at our PMTCT clinic and followed up till presentation of their infants at our 
Pediatric infectious disease clinics. This study was carried out at the Federal Teaching Hospital, Ido Ekiti (FETHI), Ekiti State, Nigeria. FETHI is one of the national ART/PMTCT and Pediatric Infectious disease clinic centers in Nigeria approved to administer HIVI AIDS care. The hospital serves as a referral center to patients from other health facilities in the adjoining Ekiti, Osun, Kwara, Kogi, and Ondo states. Eighty-five out of II5 pregnant women attending PMTCT clinic from December 2010 to March 2014 who met the study inclusion criteria, gave consent to participate, and whose infants were presented at our Pediatric infectious disease clinic for early infant diagnosis (EID) were enrolled for the study. Mothers who knew their HIV status following childbirth were excluded from the study. Combination of the pregnant women's folders and structured questionnaire were administered by the Obstetrics and Gynaecologists, and Pediatricians involved in HIVIAIDS care during the PMTCT services clinic and Paediatric Infectious Disease clinic respectively to extract social demographic, infant feeding and antiretroviral interventions data on motherinfant pair.Antiretroviral drugs were given to enrolled mothers following counseling on compliance and feeding options and HIV-exposed infants were offered post-exposure prophylaxis. CD4+ T-lymphocyte count analysis was carried out by flowcytometric technique (using Cyflow counter). Eighty-five dry blood spot (DBS) samples were obtained from infants at our PEPFAR-Supported ART laboratory and packaged for analysis at the Virology Research Centre, Obafemi Awolowo University Teaching Hospital, Ile-lfe, Nigeria after three hours of collection. This study was carried out with approval from the Ethics and Research Committee of Federal Teaching Hospital, Ido Ekiti.

\section{I Statistical analysis}

Statistical Package for Social Sciences (SPSS) version 21 was used to obtain mean \pm standard deviation of mean ages and CD4 counts of enrolled mothers and percentages of study data using simple descriptive analysis.

\section{Results}

\section{I Social demographic characteristics}

The results of the social demographic variables of the enrolled mother-infant pair were represented in Table I. Seventy (70.6\%) of the enrolled mothers had secondary/tertiary education and 73 (85.9\%) identified themselves as Christians. The overall mean age of enrolled mothers was $31.3 \pm 4.4$ years while those with HIV-positive and HIV-negative infants were $33.4 \pm 1.7$ and $31.1 \pm 4.6$ years respectively. Mean age of HIV-exposed infants at presentation was $3.9 \pm 1.2$ months. Seventy-one $(83.5 \%)$ of the infants (28 or $32.9 \%$ were males and 43 or $50.6 \%$ females) were less than 6 months at first visit, four

Table I: Social demographic characteristics enrolled mother-infant pair

\begin{tabular}{|c|c|}
\hline Social demog. variables obtained & n (\%) \\
\hline No. of enrolled mothers & $85(100.0)$ \\
\hline \multicolumn{2}{|l|}{ Educational levels } \\
\hline Below secondary & $35(4 I .2)$ \\
\hline Secondary and tertiary & $50(58.8)$ \\
\hline \multicolumn{2}{|l|}{ Religion } \\
\hline Christianity & $73(85.9)$ \\
\hline Islam & $12(14.1)$ \\
\hline \multicolumn{2}{|l|}{ Tribes } \\
\hline Yoruba & $81(95.3)$ \\
\hline Igbo & $4(4.7)$ \\
\hline Age & (Mean $\pm S D$ in years) \\
\hline $\begin{array}{l}\text { Overall mean age of enrolled } \\
\text { mothers }\end{array}$ & $31.3 \pm 4.4$ \\
\hline $\begin{array}{l}\text { Mean age of mothers with } \\
\text { HIV-positive infants }\end{array}$ & $33.4 \pm 1.7$ \\
\hline $\begin{array}{l}\text { Mean age of mothers with } \\
\text { HIV-negative infants }\end{array}$ & $3 I .1 \pm 4.6$ \\
\hline Mean Age of enrolled infants & (Mean $\pm S D$ months) \\
\hline $\begin{array}{l}\text { Mean age of } 85 \text { infants enrolled at } \\
\text { presentation }\end{array}$ & $3.9 \pm 1.2$ \\
\hline $\begin{array}{l}\text { Sex of infants presented at } \\
\text { paediatric infectious disease }\end{array}$ & n (\%) \\
\hline \multicolumn{2}{|l|}{$\leq 6$ months } \\
\hline Male & $28(32.9)$ \\
\hline Female & $43(50.6)$ \\
\hline \multicolumn{2}{|l|}{$>6 \leq 12$ months } \\
\hline Male & $4(4.7)$ \\
\hline Female & $\mathrm{I}(\mathrm{I} .2)$ \\
\hline \multicolumn{2}{|l|}{$>12 \leq 18$ months } \\
\hline Male & $6(7.1)$ \\
\hline Female & $3(3.5)$ \\
\hline
\end{tabular}

$\mathrm{SD}=$ Standard Deviation; $\mathrm{n}=$ Absolute $\%$ = Percentage

๑ 2018 Global Health and Education Projects, Inc. 
males (4.7\%) and one female ( $1.2 \%)$ infants fell within $>6 \leq 12$ years age group and six males (7.1\%) and three females (3.5\%) fell within $>12 \leq 18$ months.

\subsection{Main variables}

3.2.I Mean CD4 Counts of Enrolled Mothers Categorized Based on Infants HIV-status and Feeding Options

A total of 85 mothers with their HIV-exposed infants were recruited. Seven (8.2\%) of enrolled patients had HIV-positive infants while the rest 78 (9l.8\%) were negative. Table 2 presents the mean CD4 counts of enrolled mothers based on infants' HIV-status and feeding options. The overall mean CD4+ T-lymphocyte count of enrolled patients was $368.6 \pm 216.2 \mathrm{cells} / \mu \mathrm{l}$. The mean CD4+ T-lymphocyte count of mothers with HIV-positive and HIVnegative infants were $403.6 \pm 180.2$ cells/ $\mu \mathrm{L}$ and $387.1 \pm 224.0$ cells $/ \mu$ l respectively. Seven infants tested HIV positive, 3 of these infants (42.9\%) were exclusively breastfed while 4 (57.1\%) of the infants were on mixed feeding. The mean age and CD4+ T-lymphocytes count of mothers who breastfed their infants exclusively were $34.3 \pm 0.7$ years and $500 \pm 124$. I cells $/ \mu \mathrm{l}$ and for those who had mixed feeding were $32.7 \pm$ I.3 years and I $74.2 \pm 0.1$ cells $/ \mu$ I respectively. Similarly, based on feeding options, out of the 78 enrolled mothers with HIV-DNA negative infants based on real-time reverse-transcriptase PCR (qPCR), 73. I\% did exclusive breastfeeding, 7.7\% practiced exclusive replacement feeding, while the remaining $19.2 \%$ practiced mixed feeding. The mean age and CD4+ T-lymphocytes count of enrolled mothers with exclusive breastfeeding option were $30.6 \pm 4.6$ years and $36 \mathrm{I} . \mathrm{I} \pm 216.8$ cells $/ \mu \mathrm{L}$. Mothers of HIV-DNA negative infants with replacement feeding option had mean age and CD4+ T-lymphocytes count of $30.8 \pm 2.5$ years and $327.0 \pm 230.0$ cells $/ \mu \mathrm{l}$ while those with mixed feeding option had mean age and CD4+ T-lymphocytes count of $28.6 \pm 13.0$ years and $459.7 \pm 212.0$ cells $/ \mu \mathrm{l}$.

3.2.2 PMTCT Success Rates among Enrolled Patients Based on Antiretroviral Therapy Interventions Period and Feeding Options

Table 3 presents the data on the PMTCT success rates based on antiretroviral therapy and infant feeding options. Among the enrolled mothers with positive infants; four (57.1\%) did not use ART during the pregnancy, labor, delivery and infant feeding, $2(28.6 \%)$ were known HIV positive clients who

Table 2: Mean CD4 counts of enrolled mothers based on infants HIV-status and feeding options

\begin{tabular}{|c|c|c|c|}
\hline Overall CD4 counts & $\begin{array}{l}\text { CD4 counts of mothers } \\
\text { with }\end{array}$ & $\begin{array}{l}\text { CD4 counts of mothers with } \\
\text { HIV-negative }\end{array}$ & \\
\hline $\begin{array}{l}\text { of Enrolled mothers } \\
\text { (Cells/uL) }\end{array}$ & $\begin{array}{c}\text { HIV-positive } \\
\text { infants (Cells/ } \mu \mathrm{L})\end{array}$ & Infants (Cells/uL) & \\
\hline $368.6 \pm 216.2$ & $403.6 \pm 216.2$ & $387.1 \pm 224.0$ & \\
\hline $\begin{array}{l}\text { Feeding options of } \\
\text { mothers with HIV-DNA }\end{array}$ & $\begin{array}{l}\text { No. of enrolled } \\
\text { mothers: } n(\%)\end{array}$ & $\begin{array}{l}\text { Mean age of mothers } \\
\text { (Years) }\end{array}$ & $\begin{array}{l}\text { Mean CD4 counts of } \\
\text { mothers (Cells/uL) }\end{array}$ \\
\hline \multicolumn{4}{|l|}{ Positive infants $(n=7)$} \\
\hline Breastfeeding & $3(42.9)$ & $34.3 \pm 0.7$ & $500.0 \pm 124.1$ \\
\hline Replacement feeding & - & - & - \\
\hline Mixed feeding & $4(57.1)$ & $32.7 \pm 1.3$ & $160.0 \pm 0.0$ \\
\hline \multicolumn{4}{|l|}{ Feeding options of } \\
\hline \multicolumn{4}{|l|}{ Mothers with HIV-DNA } \\
\hline \multicolumn{4}{|l|}{ Negative infants $(n=78)$} \\
\hline Breastfeeding & $57(73.1)$ & $30.6 \pm 4.6$ & $361.1 \pm 216.8$ \\
\hline Replacement feeding & $6(7.7)$ & $30.8 \pm 2.5$ & $327.0 \pm 230.0$ \\
\hline Mixed feeding & $15(19.2)$ & $28.6 \pm 13.0$ & $459.7 \pm 212.0$ \\
\hline
\end{tabular}

HIV-DNA=Human immunodeficiency virus deoxyribonucleic acid 
Table 3: PMTCT success rate among enrolled patients based on antiretroviral therapy interventions and feeding options

\begin{tabular}{|c|c|c|c|c|c|c|c|c|c|c|}
\hline \multirow{3}{*}{$\begin{array}{l}\text { PMTCT } \\
\text { Indices }\end{array}$} & \multirow{3}{*}{$\begin{array}{l}\text { ONEM } \\
\text { n (\%) }\end{array}$} & \multicolumn{2}{|c|}{ EID RESULTS } & \multicolumn{6}{|c|}{ HAART Administration for Mothers with } & \multirow{3}{*}{$\begin{array}{c}\text { PMTCT } \\
\% \text { SR }\end{array}$} \\
\hline & & \multirow{2}{*}{$\frac{\text { Positive }}{n(\%)}$} & \multirow{2}{*}{$\frac{\text { Negative }}{n(\%)}$} & \multicolumn{3}{|c|}{ HIV-Positive Infants } & \multicolumn{3}{|c|}{ HIV-Negative Infants } & \\
\hline & & & & NN & BFPR & DUPR & NN & BFPR & DUPR & \\
\hline $\begin{array}{l}\text { Feeding } \\
\text { options }\end{array}$ & $85(100.0)$ & $7(8.2)$ & $78(91.8)$ & $4(54.1)$ & $2(28.6)$ & I (I4.3) & II (I4.I) & $27(34.6)$ & $40(5 \mid .3)$ & 91.8 \\
\hline $\mathrm{BF}$ & $60(100.0)$ & $3(5.0)$ & $57(95.0)$ & $2(67.7)$ & I (33.3) & - & 7 (II.7) & $15(25.0)$ & $35(58.3)$ & 95.0 \\
\hline RF & $6(100.0)$ & - & $6(100.0)$ & - & - & - & I (I6.7) & $3(50.0)$ & $2(33.3)$ & 100.0 \\
\hline MF & $19(100.0)$ & $\begin{array}{c}4 \\
(21.0)\end{array}$ & $15(78.9)$ & $2(50.0)$ & I (25.0) & I (25.0) & $3(20.0)$ & $9(60.0)$ & $3(20.0)$ & 78.9 \\
\hline
\end{tabular}

HIV= Human immunodeficiency virus, DNA= Deoxyribonucleic acid; Therapy Interventions and Feeding Options PMTCT= Prevention of mother-to-child transmission; $n(\%)=$ Absolute number (Percentage); ONEM = Overall number of enrolled mothers HAART= Highly active antiretroviral therapy; PMTCTSR= Prevention of mother-to-child transmission success rate; NN = None; EID = Early Infant Diagnosis; BFPR= Before pregnancy; DUPR = During pregnancy; $\mathrm{BF}=$ Breastfeeding; $\mathrm{RF}=$ Replacement feeding; $\mathrm{MF}=$ Mixed feeding.

were on ART before pregnancy and continued antiretroviral regimen during the pregnancy, while remaining one (14.3\%) commenced highly active antiretroviral therapy (HAART) only after delivery. In addition, among the enrolled mothers with negative infants, II (14.1\%) did not receive any ART, while 27 (34.6\%) and 40 (5I.3\%) respectively started HAART before and during pregnancy. The overall PMTCT success rate among the 85 enrolled women based on the combination of antiretroviral interventions and feeding options was $91.8 \%$. Early infant diagnosis results showed HIV-I prevalence of $5.0 \%, 0 \%$ and $21.1 \%$ among infants of mothers who opted for breastfeeding, replacement feeding and mixed feeding respectively. PMTCT success rates were $95 \%$ among those who chose breastfeeding; $100 \%$ among those chose replacement feeding; and $78.9 \%$ among those who chose mixed feeding.

3.2.3 Prevalence of Mother-to-child Transmission of HIVI among Exposed Infants

Figure $I$ is the bar chart that showed the prevalence of mother-to-child transmission of HIV-I among exposed male and female infants based on age groups and gender. Study results showed HIV-I prevalence of $1.2 \%$ among male infants within $>6 \leq$ I 2 months old, and HIV-I prevalence of 3.5\% among female infants aged $\leq 6$ months and 3.5\% among female infants aged $>12 \leq 18$ months.

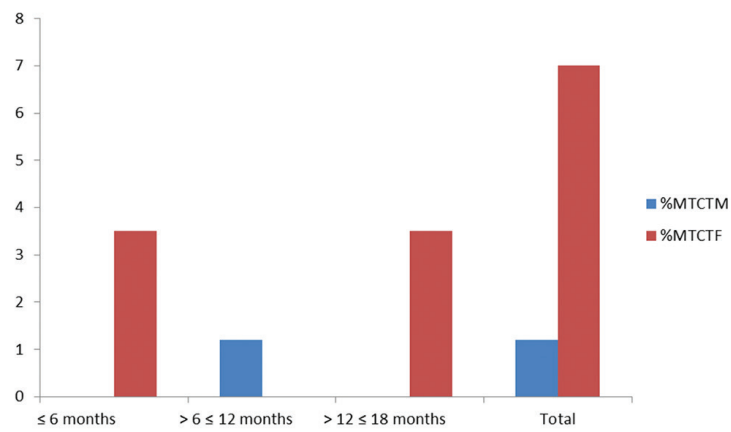

Figure I: Chart Showing Prevalence of Mother-to-child Transmission of HIV-I among Exposed Male and Female Infants Born to Enrolled Mothers.

\%MTCTM = Percentage of Mother-to-child Transmission of HIV-I among Exposed male infants; \% MTCTM = Percentage of Mother-to-child Transmission of HIV-I among exposed female infants.

\subsection{Other variables}

Paediatric Antiretroviral Interventions Success Rates in HIV-Exposed Infants

Results showing pediatric antiretroviral intervention success rates (PARTISR) in HIVexposed infants are presented in Table 4. A total of 85 HIV-exposed infants were presented at their first visit to the Paediatric Infectious Disease clinic during the 3 years and 4 months study period. Overall data showed that out of the 85 infants enrolled, only 65 (76.5\%) of the infants received post-exposure antiretroviral prophylaxis necessary 
PMTCT Success Rate Assessment:A Prospective Cohort Study

Table 4:Age group at first visit and paediatric antiretroviral interventions success rates in HIV-exposed infants/children

\begin{tabular}{lccccccc}
\hline Age (Months) & $\begin{array}{c}\text { No of enrolled infants: } \\
\mathbf{n}(\%)\end{array}$ & NVP & NVPIAZT & NT & EIDP & EIDN & Partisr (EIDN)/(EIDP+EIDN) $x$ I00\% \\
\hline$\leq 6$ & $7 I(83.5)$ & 50 & 7 & 14 & 3 & 68 & 95.8 \\
\hline$>6 \leq 12$ & $5(5.9)$ & 4 & 1 & 0 & 1 & 4 & 80.0 \\
\hline$>12 \leq 18$ & $9(10.6)$ & 3 & 0 & 6 & 3 & 6 & 66.7 \\
\hline TOTAL & $85(100.0)$ & 57 & 8 & 20 & 07 & 78 & MPARTISR=80.8\% \\
\hline
\end{tabular}

NVP=Nevirapine; NVP/AZT=Nevirapine \& Azidothymidine; EIDP=Early infant diagnosis positive; NT=Nothing; EIDN=Early infant diagnosis negative; PARTISR=Paediatric Antiretroviral therapy interventions success rates; MPARTISR=Mean Paediatric Antiretroviral therapy interventions success rates

for the prevention of mother-to-child transmission of HIV. Of these, $57(67.1 \%)$ received single-dose nevirapine, eight $(9.4 \%)$ received nevirapine and azidothymidine. a target which is still below the $95 \%$ spelt out by the National Agency for the Control of AIDS in the National HIV and AIDS strategic plan for 20I7-202I (NACA, 20I7). The PARTISR was $95.8 \%$ among infants aged $\leq 6$ months; $80.0 \%$ among infants aged $>6 \leq 12$ months and $66.7 \%$ among infants aged $>12 \leq 18$ months old. Mean PARTISR (MPARTISR) obtained in this study was $80.8 \%$.

\section{Discussion}

More than two-thirds of enrolled mothers had at least secondary education and it could be deduced that the more educated accessed PMTCT services based on the knowledge of possible risk of motherto-child transmission of HIV. ${ }^{16}$ It could not be categorically stated that predominance of enrolled mothers religious and tribal bias was responsible for research outcomes. Further studies involving predominantly pregnant women of Islamic faith or other religions, and those that enrolled patients of different tribes are needed to show the impact of religion and ethnicity on PMTCT success rates. Study also showed sex inequalities among infants born to HIV-exposed mothers and presented at the Pediatric Infectious Disease (PID) clinic at different age groups.

The risk of having HIV-positive infants might not be maternal-age-dependent but highly dependent on the CD4 counts as revealed by slightly increased mean CD4 counts among those with infants who were HIV-positive ( $403 \pm 180$ cells $/ \mu \mathrm{L})$ and supported by a number of studies. ${ }^{17-20}$ This study showed maternal- to-child transmission of HIV-I of $8.2 \%$. This was far lower than the national MTCT rate of nearly $32 \%{ }^{16}$ and more than $60 \%$ above the $5.0 \%$ recommended by the WHO. ${ }^{21}$ Moreover, evidence showed that the HIV-status of exposed infants did influence the feeding option choices of mothers' post-partum or post-natal. Only $43.0 \%$ of patients on PMTCT program chose to exclusively breastfeed their HIVpositive infants despite the higher mean CD4 counts $500 \pm 124$ cells $/ \mu \mathrm{L}$ compared to $73.1 \%$ of those with HIV-negative exposed infants with mean CD4 count of $36 \mathrm{I} . \mathrm{I} \pm 216.8$ cells $/ \mu \mathrm{L}$. What accounts for this difference remains unclear and requires further research.

Similarly, $57.1 \%$ of mothers with HIV-positive babies chose mixed feeding compared to $19.2 \%$ of those with HIV-negative exposed babies. Selection of mixed feeding option by the former category of mothers especially among those with HIV-positive infants could probably be due to their waned immune status as evidenced by lower CD4 counts $(160 \pm 0.1$ cells $/ \mu \mathrm{L})$. The negative attitude of patients to option $\mathrm{B}+$ in our facility following transition from option B guideline in 2013 might partly be responsible for the overall PMTCT success rate of 91.8\% obtained in this study as corroborated by a prior study. ${ }^{22} \mathrm{~A}$ report on prevention gap by the Joint United Nations Program on HIVIAIDS indicated that treatment drop-outs rate among pregnant and breastfeeding women remain high and that contributed to increased risk of HIV transmission to the children. ${ }^{19}$ In this regard, some of the HIVpositive mothers on antiretroviral therapy might not have complied $100 \%$ with drug taking during pregnancy or while breastfeeding. However, the 
MTCT of $8.2 \%$ achieved in our center is noteworthy when compared to Nigeria's national MTCT rate of 32 percent. Assessment of the PMTCT success rate among mothers based on combined ART interventions and feeding options showed an outcome of $95.0 \%, 100 \%$ and $78.9 \%$ among mothers with exclusive breastfeeding, exclusive replacement feeding and mixed feeding options respectively. The risk of MTCT among HIV-positive women who opted for mixed feeding was greater than $\mathrm{I}$ in 5 compared to I in 20 among those who chose to exclusively breastfeed. Prior studies in Nigeria ${ }^{23}$ and South Africa ${ }^{10}$ confirmed the strong association between mixed feeding and high MTCT especially within the first six months of life compared to the exclusively breastfed infants. Evidence from this study lends credence to the need to emphasize exclusive breastfeeding among HIV-positive women irrespective of the status of their infants as long as the mother was on ART and the infant is on ART prophylaxis. Zero percent MTCT report from this study on babies that were formula-fed showed that exclusive replacement feeding may be a suitable alternative in non-breastfeeding mothers.

Again, this study established that gender of infants born to HIV-positive mothers played a role in maternal-to-child transmission of HIV. Female infants were more at risk of HIV infection through vertical transmission than their male counterparts. This finding was consistent with outcomes of other studies. ${ }^{24,25,26}$ Khobondo et al reported 2.5-fold prevalence among female in Nairobi than male infants in 2015 while the outcome of this study showed nearly 6-fold HIV prevalence. Studies have clarified the mechanisms behind the factors attributed to this difference. Genetic, epigenetic, hormonal and immunologic factors have been identified..$^{25,27}$

Moreover, the Pediatric antiretroviral therapy intervention success rate (PARTISR) decreased as the infants age-group at presentation increased. That is, age of infants at presentation is a risk factor of MTCT in HIV-exposed infants. Evidence showed that the post-exposure prophylaxis of single dose nevirapine for the first six weeks of breastfeeding is effective. Similarly, daily administration of nevirapine prophylaxis for 4-6 weeks or twice daily azidothymidine (AZT) for children that were exclusively formula fed has proven to be effective in preventing MTCT.The average time from birth to presentation at PID of all infants was $3.9 \pm 1.2$ months. The inverse relationship observed between PARTISR and the infants age-groups at presentation may be attributable to decreasing compliance to ART, late presentation due to loss to follow up predicated by the negative attitudes of HIV-infected mothers to PMTCT as well as social-economic factors that led to prolonged breastfeeding of infants especially those in the $>12 \leq 18$ months age group which might have been counter-productive in mothers and infants who received nothing.

\section{Limitations}

Impact of religion, ethnicity and marital status on PMTCT outcomes could not be established in this study. Whether these constitute risk factors of MTCT requires further research. Certain risk factors may contribute to transmission of HIV-I among exposed infants in-utero, postpartum and postnatal but this study did not capture these different phases neither did it capture the diagnosis period or years of being on ART prior to pregnancy and option full $\mathrm{B}+$ implementation.

\section{Recommendation for further studies}

Future studies should explore the impact of religion, ethnicity and marital status on PMTCT outcomes. Future studies should also examne outcomes of full option $\mathrm{B}+$ implementation in rural settings, and MTCT risk factors for in-utero, intrapartum and postnatal infections.

\section{Conclusions and Global Health Implications}

In this study, we found that the combination of effective PMTCT interventions and breastfeeding is important for successful prevention of motherto-child-transmission of HIV to exposed infants. Implementation of more clinical interventions as well as service interventions including effective follow up methods and more productive counseling on feeding options in our settings can further reduce the scourge of HIVIAIDS epidemics among exposed infants and improve outcomes. 


\section{Key Messages}

- Planning and implementation of exclusive breastfeeding of infants of HIV-infected women irrespective of infants' status is key to successful PMTCT program..

- Evidence suggests the need for more pragmatic strategies to ensure full compliance of mother-infant pairs to ART through proper follow-up for successful PMTCT outcomes.

- Mixed feeding continues to contribute to increased risk of MTCT among HIV-exposed infants, thus stakeholders involved in PMTCT services must be well-equipped for effective counseling of pregnant women on feeding options' risks and benefits.

\section{Compliance with Ethical Standards}

Conflicts of Interest: Authors declared there was no conflict of interest regarding this study. Financial Disclosure: Authors declared there we had no financial disclosure to make for this research. Funding/Support: This study was supported with antiretroviral drugs by the implementing partners through Federal Teaching Hospital, Ido Ekiti, Ekiti State, Nigeria. Ethics Approval: This study was carried out with approval from the Ethics and Research Committee of Federal Teaching Hospital, Ido Ekiti, Ekiti State, Nigeria.

\section{References}

I. Sama, CB, Feteh VF, Tindong M, Tanyi JT, Bihle NM, Angwafo FF. Prevalence of maternal HIV infection and knowledge on mother-to-child transmission of HIV and its prevention among antenatal care attendees in a rural area in northwest Cameroon. PLoS One. 2017; I2: e0172102.

2. Gamell, A, Luwanda LB, Kalinjuma AV, Samson L, Ntamatungiro AJ, Weisser M, Gingo W, Tanner M, Hatz C, Letang E, Battegay M. Prevention of motherto-child transmission of HIV Option B+ cascade in rural Tanzania:The One Stop Clinic model. PLoS One. 2017; 12: e0181096.

3. Agboghoroma, C., Sagay, S. \& Ikechebelu, J. Nigerian prevention of mother to child transmission of human immunodeficiency virus program: The journey so far. J. HIV Human Reproduction. 2013; I:I-7.
4. Kassa, G. M. Mother-to-child transmission of HIV infection and its associated factors in Ethiopia: a systematic review and meta-analysis. BMC Infect Dis. 2018; 18:216 (2018).

5. World Health Organization. HIV transmission through breastfeeding: a review of available evidence: 2007 update. Reprod. Health Matters (2008). doi:10.1016/S0968-8080(99)90058-7

6. UNAIDS. Global report: UNAIDS report on the global AIDS epidemic 20I0. 3, 229-230 (20I0).

7. van Lettow, M, Bedell R, Landes M, Gawa L, Gatto S, Mayuni I, Chan AK, Tenthani L, Schouten E. Uptake and outcomes of a prevention-of mother-to-child transmission (PMTCT) program in Zomba district, Malawi. BMC Public Health. 20 I I; I I:426.

8. Federal Ministry of Health. 2014 National HIV Seroprevalence Sentinel Survey among Pregnant Women Attending Antenatal Clinics in Nigeria. Department of Public Health. National AIDS/STI Control Program. 2015; 18-23.

9. National Agency for the Control of AIDS. National HIV and AIDS Strategic Plan 2017-202I. Prevention of Mother-to Child Transmission. 2017.

10. Coovadia, H. M, Coovadia HM, Rollins NC, Bland RM, Little K, Coutsoudis A, Bennish ML, Newell M-L. Mother-to-child transmission of HIV-I infection during exclusive breastfeeding in the first 6 months of life: an intervention cohort study. Lancet (London, England) 2007; 369: I 107-1 I I6.

II. Doherty T, Sanders D, Goga A, Jackson D. Implications of the new WHO guidelines on HIV and infant feeding for child survival in South Africa. Bull. World Health Organ. 201 I: 89, 62-67.

12. WHO. Guidelines on HIV and Infant Feeding: Principles and recommendations for infant feeding in the context of HIV and summary of evidence. World Health Organization. Geneva (20I0).

13. Marinda, P., Chibwe, N., Tambo, E., Lulanga, S. \& Khayeka---Wandabwa, C. Challenges and opportunities of optimal breastfeeding in the context of HIV option B+ guidelines. BMC Public Health 17,54I (2017).

14. Nabwera HM, Jepkosgei J, Muraya KW, Hassan AS, Molyneux CS, Ali R, Prentice AM, Berkley JA, Mwangome MK. What influences feeding decisions for HIV-exposed infants in rural Kenya? International Breastfeeding Journal. 20I7: I2: 31-4I. 
15. MoH. Guidelines for Prevention of Mother To Child Transmission (PMTCT) of HIV/Aids in Kenya. (2009). doi:JC2502/I/E

16. Abiodun O, Sotunsa J, Olu-Abiodun O,Ani F,Taiwo A, Taiwo O., The Effect of Training on Traditional Birth Attendants' PMTCT Related Knowledge and Care Practices in Nigeria.J.AIDS Clin. Res. 2015; 06: 498.

17. Coutsoudis, A. et al. Late postnatal transmission of HIV-I in breast-fed children:an individual patient data meta-analysis. J. Infect. Dis. 189, 2I 54-2166 (2004).

18. Afe, AJ, Haroun, I, Edet-utan, K, Akinmurele T. Effect of test- and -treat strategy on antiretroviral drugs uptake in a prevention of mother to child transmission program in Southwest Nigeria. Sci. J. Public Health. 20I4; 2:476-479.

19. UNAIDS. Prevention Gap Report 2016.83, 286 (2016).

20. Iloh KK, Iloh ON, Ikefuna AN, Ibeziako NS, Ubesie AC, Emodi IJ. Determinants of motherto-child transmission of HIV despite PMTCT interventions in Enugu, Nigeria. The South African Journal of Child Health. 20I5; 9(2): 49-52

21. WHO. Mother-to-child transmission of HIV. World Health Organization (2016). Available at: http://www. who.int/hiv/topics/mtct/about/en/\#.W03tH7LGM-g. mendeley. (Accessed: $17^{\text {th }}$ July 2018)
22. Olugbenga-Bello, A. I., Adebimpe, W. O., Osundina, F. F. \& Abdulsalam, S. T. Perception on prevention of mother-to-child-transmission (PMTCT) of HIV among women of reproductive age group in Osogbo, Southwestern Nigeria. Int. J. Womens. Health 5, 399-405 (20I3).

23. Charurat M, Datong P, Matawal B,AjeneA, BlattnerW, Abimiku A.Timing and Determinants of Mother-toChild Transmission of HIV in Nigeria. Int J Gynaecol Obstet. 2009; 106(I): 8-13.

24. Adejuyigbe EA, Oyelami O, Onayemi O, Durosimi MA. Paediatric HIV/AIDS in lle Ife, Nigeria. Cent Afr J Med. 2003; 49 (7-8): 74-78.

25. Khobondo JO, Gicheru MM, Khamadi S. A. Pediatric HIV-AIDS in Nairobi; prevalence, gender and implication for prevention of mother to child transmission. Eur.J. Res. Med. Sci. 20I5; 3:52-59.

26. Taha TE, Nour S, Kumwenda NI, Broadhead RL, Susan A. Fiscus SA, Kafulafula G, Nkhoma C, Chen S, Hoover DR. Gender Differences in Perinatal HIV Acquisition Among African Infants. Pediatrics. 2005; II5: el67 LP-el72.

27. Garenne, M. Sex ratios at birth in African populations: a review of survey data. Hum. Biol. 74, 889-900 (2002). 